\title{
The selectivity of $n$-hexane hydroconversion on MOR-, MAZ-, and FAU-type zeolites
}

\author{
Sofia Calero ${ }^{a}$, Merijn Schenk ${ }^{b}$, David Dubbeldam ${ }^{b}$, Theo L.M. Maesen ${ }^{c, *}$, Berend Smit ${ }^{b}$ \\ ${ }^{a}$ Department of Experimental Science, University Pablo de Olavide, Ctra de Utrera, Km. 1, 41013 Seville, Spain \\ ${ }^{\mathrm{b}}$ Department of Chemical Engineering, University of Amsterdam, Nieuwe Achtergracht 166, 1018 WV, Amsterdam, The Netherlands \\ c ChevronTexaco, Energy Technology Company, 100 Chevron Way 10-1412, Richmond, CA 94802-0627, USA
}

Received 26 April 2004; revised 23 July 2004; accepted 5 August 2004

Available online 29 September 2004

\begin{abstract}
Analyses of a series of published $n$-hexane hydroisomerization product slates suggest that MAZ-type zeolites yield more dimethylbutane and less methylpentane than either FAU- or MOR-type zeolites. Molecular simulations do not corroborate the traditional view that these selectivity differences are specifically related to the MAZ-, FAU-, or MOR- type zeolite topology. A scrutiny of the literature indicates that reported variation in selectivity relates to a variation in the efficiency of the (de)hydrogenation function relative to the acid function. The FAU-type zeolite catalyst had the most efficient hydrogenation function. The efficiency of the hydrogenation function on the MAZ-type zeolite was low enough to significantly enhance the 2,3-dimethylbutane yield relative to the methylpentane yield, but not low enough to decrease the 2,2-dimethylbutane yield. The efficiency of the hydrogenation function on the MOR-type zeolite was low enough to do both. Only at a sufficiently high $n$-hexane hydroconversion does the catalyst with the most efficient hydrogenation function exhibit the highest dimethylbutane yield. This new perspective on the reported hexane hydroconversion selectivities suggests that a FAU-type zeolite catalyst with a highly efficient hydrogenation function is best suited for $n$-hexane hydroisomerization. The FAU topology has the highest porosity which should afford the highest activity without impairing selectivity.
\end{abstract}

(c) 2004 Elsevier Inc. All rights reserved.

Keywords: MAZ-type zeolite; MOR-type zeolite; FAU-type zeolite; $n$-Hexane hydroconversion; Kinetics; Shape selectivity

\section{Introduction}

The importance of upgrading light naphtha (pentane and hexane) streams in refineries continues to increase as environmental regulations on gasoline composition continue to evolve [1-4]. There are four distinct noble metal-loaded catalysts available commercially to increase the octane number of the combined pentane and hexane fraction: (1) chlorided alumina [5], (2) MOR-type zeolites [6,7], (3) sulfated [8-13], and (4) tungstentated [14-17] zirconia. All of these catalysts bring the pentane and hexane feed to gasphase thermodynamic equilibrium. As the octane number of this thermodynamic equilibrium mixture increases with de-

\footnotetext{
* Corresponding author. Fax: (510) 242-2823.

E-mail address: tmaesen@ chevrontexaco.com (T.L.M. Maesen).
}

creasing operating temperature, chlorided alumina increases the octane number the most, for it operates at the lowest temperature [1-4]. MOR-type zeolite increases the octane number the least, for it operates at the highest temperature. Nonetheless MOR-type zeolites have often replaced catalysts based on chlorided alumina because zeolites are significantly less sensitive to contaminants in the feed and to other operational upsets $[3,4]$. The operation temperature and robustness of sulfated and tungstentated zirconia are intermediate between those of chlorided alumina and zeolites. Further improving the robustness and decreasing the operation temperature of the novel zirconia-based catalysts appears to be a major focus of current research [10-17]. An alternative approach would be to search for a zeolite that affords improvements over the traditional MOR-type zeolites. 
In the early 1990s, it was suggested that MAZ-type zeolites are inherently better suited than MOR-type zeolites for yielding high-octane pentane and hexane [18-20]. An equitable comparison between the performance of MAZand MOR-type zeolites turned out to be remarkably complicated, for the accessibility [21-27], density, and strength $[7,28,29]$ of the Brønsted acid sites all appear critically dependent on the zeolite synthesis [23,30-34] and modification $[23,35,36]$ processes. After nearly a decade of research, it was concluded that the improvement of MAZ- over MORtype zeolites was too small to merit commercialization of the former [29,37]. Probably as a result of the experimental complexity, the fundamental reasons for the manifestation $[18,19]$ of significantly higher octane numbers obtained with MAZ- over MOR-type zeolites have never been elucidated.

Recently we have used molecular simulations $[38,39]$ to elucidate why MAZ-type zeolites are optimally suited for the production of high-octane-number light naphtha (particularly highly branched hexane isomers) in the hydrocracking of complex industrial feeds [40]. Our analysis shows that MAZ-type zeolites have the optimum pore size to impose an adsorbed phase thermodynamic equilibrium that favors formation of the shortest, most highly branched hexane isomers $[38,39]$. However, the adsorbed-phase thermodynamic equilibrium can only imprint its signature on the gas-phase product slate if two conditions are met: (1) a high boiling point feed produces and traps the hydroisomerizing hexane isomers in the adsorbed phase, and (2) the higher boiling point feed impedes subsequent readsorption of hexane products $[38,39]$. Theoretically, if hexane is free to adsorb and desorb, it should simply hydroisomerize toward gas-phase thermodynamic equilibrium and there would be no significant differences between the selectivities of FAU-, MAZ-, and MOR-type zeolites. Surprisingly, the higher-branched hexane yield observed with the MAZ-type zeolites under discussion was reportedly obtained without any obvious impediment to hexane adsorption or desorption, using either light naphtha [18] or $n$-hexane [19,20] as feed. This raises the question if our previous analysis was somehow incomplete: Can the MAZ-type zeolite topology affect the hexane product slate in some other way, in the absence of a feed component with a higher boiling point?

By definition, the unambiguous effect of a zeolite topology on the product slate is an instance of shape selectivity. As part of an effort to gain a fundamental understanding of shape selectivity we have employed molecular simulations to elucidate the relevant processes at a molecular level $[38,39,41,42]$. Research so far suggests that the fate of a molecule depends on the relative heights of the Gibbs free energies of adsorption of reactants, intermediates, and products and the relative heights of the Gibbs free energy barriers to adsorption, reaction, diffusion, and desorption (Fig. 1). Five forms of shape selectivity can occur (Fig. 2):

I. Reaction intermediate shape selectivity [41,43]: Inside zeolites, reaction intermediates approach an equilibrium

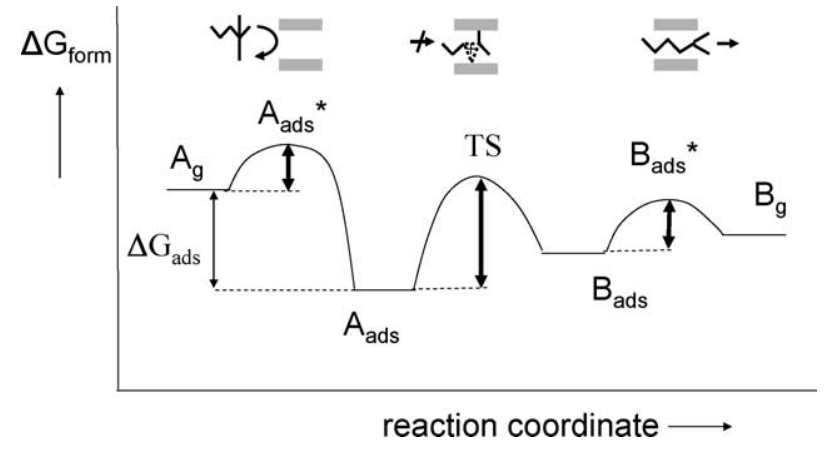

Fig. 1. Change in Gibbs free energy of formation, $\Delta G_{\text {form }}$, when gas-phase molecule $A_{g}$ equilibrates with gas-phase $B_{g}$ through formation of reaction intermediates $\mathrm{A}_{\mathrm{ads}}$ and $\mathrm{B}_{\mathrm{ads}}$ physisorbed inside a zeolite catalyst. The Gibbs free energy of formation of $\mathrm{A}_{\mathrm{ads}}$ and $\mathrm{B}_{\mathrm{ads}}$ is determined by the sites where $\mathrm{A}_{\mathrm{ads}}$ and $\mathrm{B}_{\mathrm{ads}}$ are most commensurate with the zeolite topology. $\mathrm{A}_{\mathrm{g}}$ and $\mathrm{B}_{\mathrm{g}}$ can reach these sites only by moving through positions at which they fit less well. $\mathrm{A}_{\mathrm{ads}}{ }^{*}$ and $\mathrm{B}_{\mathrm{ads}}{ }^{*}$ mark the positions with the worst fit and, therefore, the highest free energy of formation. By definition the Gibbs free energy of adsorption is the difference in Gibbs free energy of formation between gas and adsorbed phase, i.e., between $A_{g}$ and $A_{a d s}$. The Gibbs free energy barrier to diffusion and desorption is the difference in Gibbs free energy of formation between $\mathrm{A}_{\mathrm{ads}}$ and $\mathrm{A}_{\mathrm{ads}}{ }^{*}$. Strictly speaking, the Gibbs free energy barrier to adsorption is the difference in free energy of formation between $\mathrm{A}_{\mathrm{g}}$ and $\mathrm{A}_{\mathrm{ads}}{ }^{*}$. However, for the purpose of this article, we equate the Gibbs free energy barrier to adsorption with that to diffusion on the assumption that the diffusion of a molecule from the exterior surface to the crystal's interior surface limits the adsorption rate. The chemical processes that turn $\mathrm{A}_{\mathrm{ads}}$ into $\mathrm{B}_{\mathrm{ads}}$ were lumped into a single transition state (TS). The Gibbs free energy barriers were labeled with a pictogram illustrating the corresponding form of shape selectivity (see Fig. 2).

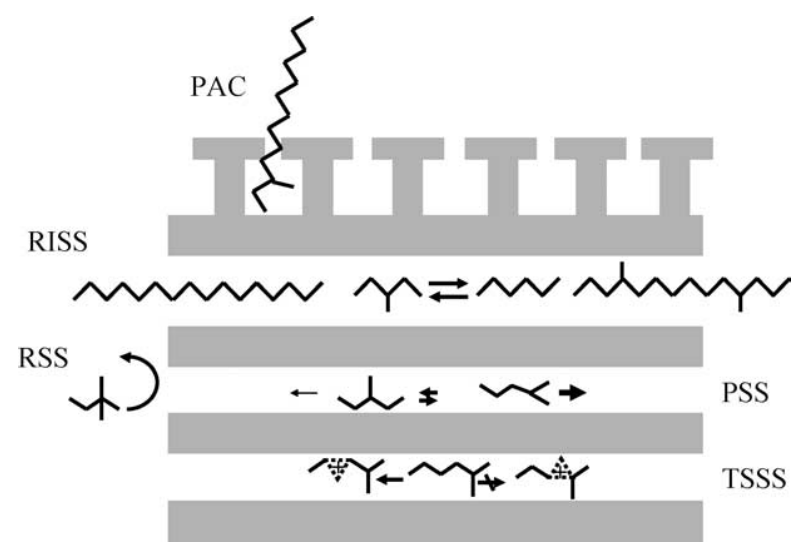

Fig. 2. Illustration of the five basic forms of shape selectivity. (I) Reaction intermediate shape selectivity (RISS): Adsorbed $n$-hexane and 3-methylpentane are formed through hexadecane hydrocracking rather than hexane adsorption. Adsorbed hexadecane prevents adsorption of hexane, so that hexane in the adsorbed phase cannot equilibrate with hexane in the gas phase. It does not prevent desorption of hexane, so that the gas-phase product slate reflects the approach toward the thermodynamic equilibrium distribution of the adsorbed phase rather than the gas-phase hexanes. (II) Partial adsorption catalysis (PAC): When complete adsorption of tetradecane is blocked, it can still react through partial adsorption at the galleries near the exterior surface. (III-V) When the zeolite topology specifically alters the Gibbs free energy barrier to reactant adsorption, reaction, or product desorption, a reaction can exhibit reactant (RSS), transition state (TSSS), and product (PSS) shape selectivity, respectively. Reactant and product shape selectivity occur only when the rate of reactant adsorption or that of product desorption limits the reaction rate. 
defined by the Gibbs free energies of formation in the adsorbed state. If the Gibbs free energy barrier to diffusion is high enough to impede equilibration between gas and adsorbed phases, the adsorbed-phase reaction intermediate concentration affects the gas-phase product slate $[38,39,44,45]$.

II. Partial adsorption catalysis: Zeolites preferentially process reactants at the exterior surface if they exhibit too high a Gibbs free energy of adsorption [42] or too high a Gibbs free energy barrier to adsorption [46-48] to fully penetrate the adsorbent.

III. Reactant shape selectivity [41,49]: When the adsorption rate limits the reaction rate, zeolites preferentially consume reactants that combine a low Gibbs free energy of adsorption with a low Gibbs free energy barrier to adsorption.

IV. Product shape selectivity [41,49]: When the desorption rate limits the reaction rate, zeolites preferentially yield products that combine a high Gibbs free energy of adsorption with a low Gibbs free energy barrier to desorption.

V. Transitions state shape selectivity: Zeolites preferentially form transition states with the lowest Gibbs free energy of formation [43,50-52].

When adsorbate-adsorbent interactions are taken in isolation, the Gibbs free energy of adsorption is determined by the site at which the adsorbent and adsorbate topologies are most commensurate; the diffusion rate is determined by the site at which they are least commensurate (Fig. 1) [45,53]. In addition to adsorbate-adsorbent interactions, intermolecular interactions among reactants, intermediates, and products affect the Gibbs free energy of adsorption [38,39] and the rates of adsorption, diffusion, and desorption [38,39,46].

In this article, we first describe the mechanism of $n-\mathrm{C}_{6}$ hydroconversion. Subsequently, we discuss the reported selectivity differences between FAU-, MAZ-, and MOR-type zeolites. An evaluation of the $\mathrm{C}_{6}$ isomer composition inside the pores of these zeolites at thermodynamic equilibrium provides an assessment of the likelihood of shape selectivity. Finally, evaluation of the effects of the relative efficiency of the (de)hydrogenation function and acid function suggests a more rigorous explanation for the reported variation in hydroconversion selectivity.

\section{Molecular simulation methods}

To study the driving forces behind shape selectivity of various zeolites, one needs detailed information at the molecular level about the adsorbed hydrocarbons. We obtain this information by using computer simulations based on the configurational-bias Monte-Carlo (CBMC) technique.

The configurational-bias Monte-Carlo technique affords an efficient calculation of the thermodynamic properties and adsorption isotherms of hydrocarbons in nanoporous sil- ica structures [38,39]. In the CBMC scheme the molecules are grown bead, by bead biasing the growth toward energetically more favorable conformations and thus avoiding overlaps with the zeolite. This results in a sampling scheme that is orders of magnitude more efficient than traditional Monte-Carlo schemes, where entire molecules are inserted at once, generating a high percentage of unlikely or impossible configurations in the process. Because of its efficiency, the CBMC scheme allows us to obtain information about hydrocarbons as large as hexadecane $\left(\mathrm{C}_{16}\right)[38,39]$.

Our CBMC simulation model uses single interaction centers (united atoms) to represent the $\mathrm{CH}_{3}, \mathrm{CH}_{2}, \mathrm{CH}$, and $\mathrm{C}$ groups in the linear and branched alkanes. The bonded interactions include bond-bending and torsion potentials. Dispersive interactions with the oxygen atoms of the silica structure are assumed to dominate the silica-alkane interactions. The zeolite is modeled as a rigid crystal [54] consisting exclusively of $\mathrm{SiO}_{2}$, so as to make the calculation of alkanezeolite interactions efficient by using special interpolation techniques [55,56]. The sizes of the molecules and the energy parameters have been fitted to faithfully reproduce the experimentally determined isotherms (particularly the inflection points) on MFI-type zeolites over a wide range of pressures and temperatures [57]. The resultant force field reproduces the Henry coefficients, enthalpies, and entropies of adsorption and maximum loading extremely well [57]. The same force field also reproduces these parameters remarkably well for nanoporous silica topologies other than the MFI type [57]. More details about the simulation method and the force fields are described elsewhere [57].

Research octane number ( $\mathrm{RON})$ values of isomer mixtures were calculated from the research octane numbers of the individual components as determined by ASTM 2699: $24.8,73.4,74.5,100.3$, and 91.8 for $n$-hexane $\left(n-\mathrm{C}_{6}\right)$, 2-methylpentane (2-MP), 3-methylpentane (3-MP), 2,3-dimethylbutane (2,3-DMB), and 2,2-dimethylbutane (2,2DMB), respectively [58].

\section{Results and discussion}

\section{1. $C_{6}$ hydroconversion mechanism}

In $n$-hexane $\left(n-\mathrm{C}_{6}\right)$ hydroconversion, a metal site dehydrogenates $n-\mathrm{C}_{6}$ into an alkene, an acid site converts the alkene into another isomer or a cracking product, whereupon the metal site hydrogenates the converted alkene back into an alkane [59-61]. When starting with an $n$-hexene, $n-\mathrm{C}_{6}^{=}$, the hydroconversion can be described as a series of consecutive hydroisomerization steps, initially forming 2and 3-methylpentenes (2- and 3-MP $=$, respectively), subsequently 2,3- and 2,2-dimethylbutenes (2,3- and 2,2-DMB=, respectively) (Fig. 3) [62,63]. Equilibration between 2-, $3-\mathrm{MP}^{=}$and the corresponding alkanes is extremely rapid, so that 2- and 3-MP are produced at their gas-phase thermodynamic equilibrium ratio for conversions above $\sim 15 \% n-\mathrm{C}_{6}$ 


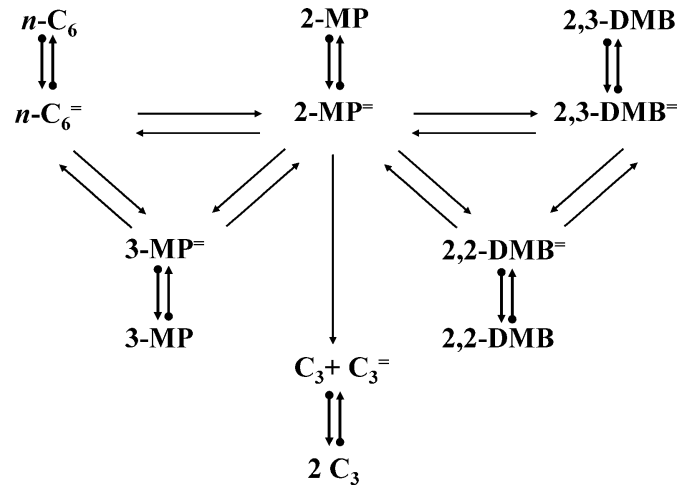

Fig. 3. Traditional $n-\mathrm{C}_{6}$ hydroconversion mechanism [59-63,72,76,77]:

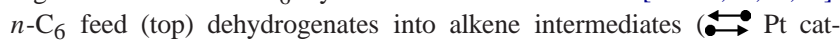
alyzed). At acid sites, hexene isomers undergo isomerizations toward thermodynamic equilibrium ( $\leftrightarrows$, acid catalyzed). After acid-catalyzed reaction

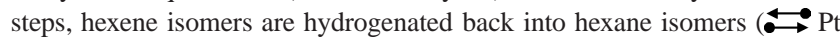
catalyzed). Propene hydrocracking products are hydrogenated into propane $(\leftrightarrow$ Pt catalyzed). Assuming the that all changes in the degree of branching occur through protonated alkylcyclopropyl cations, we have added the direct hydroisomerization of $2-\mathrm{MP}^{=}$into $2,2-\mathrm{DMB}^{=}$to the traditional scheme. Traditionally this pathway has been omitted $[15,72,76]$, because rapid 2,2-DMB $=$ formation does not necessarily entail rapid 2,2-DMB formation. 2,2-DMB formation requires a (rarely observed) highly efficient hydrogenation function [15,28,63] (cf. Fig. 5).

conversion [20,63]. Equilibration between 2,3- and 2,2$\mathrm{DMB}^{=}$is probably also extremely rapid, but equilibration with the corresponding alkanes is slow $[15,63]$. Therefore, 2,3- and 2,2-DMB tend to appear as consecutive hydroisomerization products. Of the five $\mathrm{C}_{6}$ isomers 2-MP is the only one that can hydrocrack into propane $\left(\mathrm{C}_{3}\right)$ and propene $\left(\mathrm{C}_{3}=\right)$ albeit with difficulty $[61,63]$. Therefore, hydrocracking tends to become significant only above $\sim 70 \mathrm{~mol} \% n-\mathrm{C}_{6}$ hydroconversion $[15,20,63]$.

\subsection{Selectivity differences}

According to the $n-\mathrm{C}_{6}$ hydroconversion mechanism, $n-\mathrm{C}_{6}$ initially yields 2- and 3-MP and, subsequently, 2,3and 2,2-DMB. Equilibration between 2- and 3-MP occurs at low conversion; equilibration between 2,3- and 2,2-DMB requires a considerably higher $n-\mathrm{C}_{6}$ conversion. A low-acidsite-density, high-platinum-site-density FAU-type zeolite affords an illustrative example of this consecutive formation of $\mathrm{C}_{6}$ isomers from $n-\mathrm{C}_{6}$ (Fig. 4A) [63]. Corroborating results were reported by other research groups $[64,65]$. The selectivity of this catalyst is representative of $n-\mathrm{C}_{6}$ hydroconversion in the absence of shape selectivity, for similar selectivities were reported in the absence of a well-defined topology [15]. The FAU-type pores are too large as compared with the $\mathrm{C}_{6}$ isomers to imprint their signature on the $n-\mathrm{C}_{6}$ hydroconversion selectivity $[41,45,61,63]$. The MAZand MOR-type pores are smaller [66], so that these topologies could imprint their signature on the $n-\mathrm{C}_{6}$ product slate. Indeed, both MAZ- and MOR-type zeolites reportedly yield more DMB and less MP than FAU-type zeolites [20,63]: the MAZ-type zeolite converts more 2-MP into 2,3-DMB

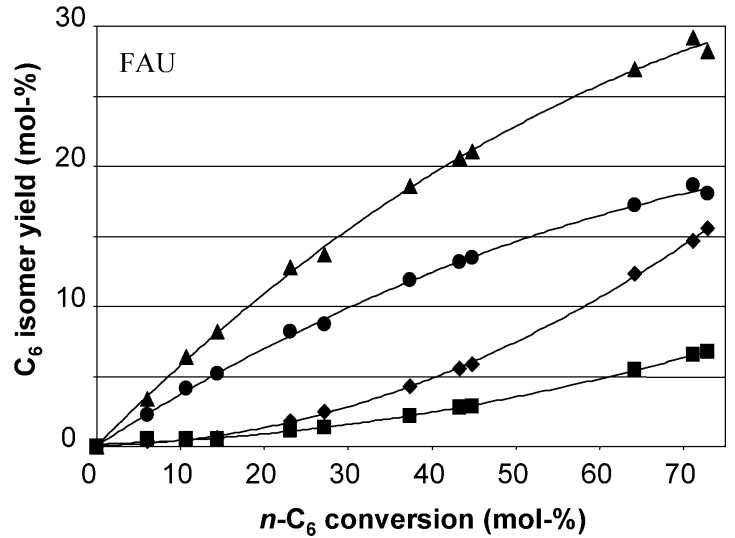

(A)

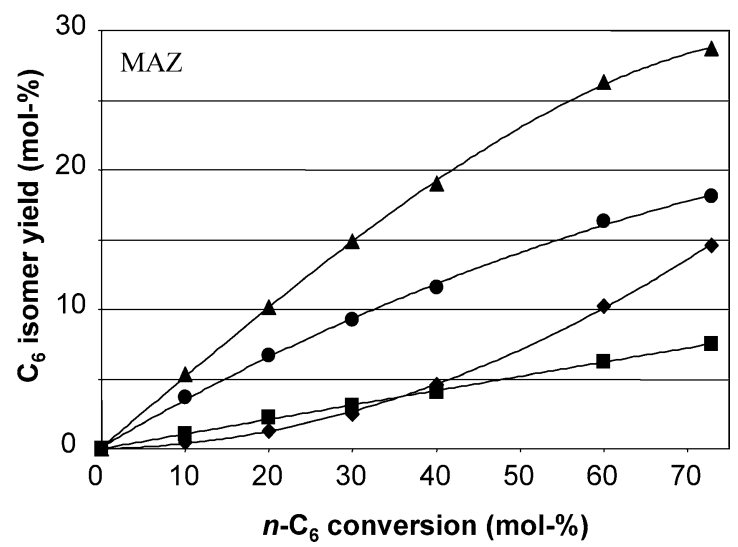

(B)

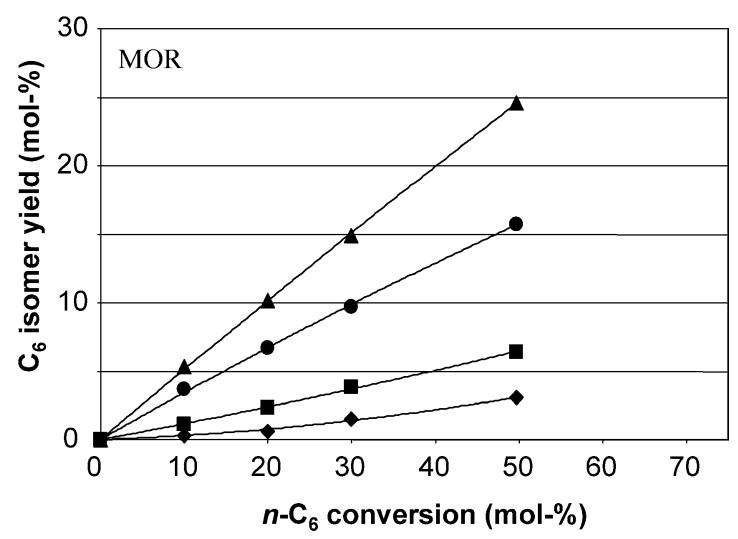

(C)

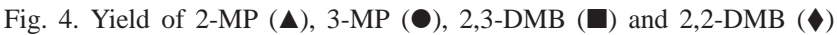
$(\mathrm{mol} \%)$ as a function of $n-\mathrm{C}_{6}$ hydroconversion for (A) FAU-, (B) MAZ-, and (C) MOR-type zeolites. Data were adapted from Refs. [20,63].

than the FAU-type zeolite, and converts slightly less 2,3into 2,2-DMB [20,63]. The MOR-type zeolite also converts more 2-MP into 2,3-DMB, and converts significantly less 2,3- into 2,2-DMB (Table 1, Fig. 4) [20,63]. Corroborating results were reported by another research group [19,29], so that these results appear representative of the zeolite-based catalysts under discussion. Some of the corroborating data [19] are less useful for the present analysis, for the reported 2,3-DMB-to-2-MP yield ratios are well in excess of the thermodynamic equilibrium value (as calculated from data 
Table 1

Differences in $n-\mathrm{C}_{6}$ hydroconversion selectivity for platinum-loaded zeolite catalysts at $30 \% n-\mathrm{C}_{6}$ conversion and negligible yield of cracking products ${ }^{\mathrm{a}}$

\begin{tabular}{llll}
\hline & FAU & MAZ & MOR \\
\hline Source & 1.5 PtHY3 & PtHMAZ30 & PtHMOR \\
& {$[63]$} & {$[20]$} & {$[20]$} \\
$T(\mathrm{~K})$ & 523 & 533 & 533 \\
$p \mathrm{C}_{6}(\mathrm{kPa})$ & 10 & 300 & 300 \\
$\mathrm{H}_{2} / \mathrm{C}_{6}(\mathrm{~mol} / \mathrm{mol})$ & 9 & 9 & 9 \\
Composition (mol\%) & & & \\
$\quad$ 2-MP & 52.0 & 49.5 & 49.7 \\
3-MP & 33.3 & 32.0 & 32.4 \\
2,3-DMB & 5.3 & 10.2 & 12.8 \\
2,2-DMB & 9.4 & 8.3 & 5.1 \\
MP & 85.3 & 81.5 & 82.1 \\
DMB & 14.7 & 18.5 & 17.9 \\
\hline
\end{tabular}

a The FAU-type zeolite catalyst yields significantly less 2,3-DMB than the other catalysts. The MOR-type zeolite yields significantly less 2,2-DMB than the other catalysts.

provided by Refs. $[4,67])$, suggesting that the catalysts were not properly lined out. These experimental issues aside, the fundamental question that has remained unanswered is why these MAZ- and MOR-type zeolites yield $\mathrm{C}_{6}$ isomer mixtures different from those obtained on FAU-type zeolites.

\subsection{Does selectivity relate to pore topology?}

The predominant speculation regarding the higher DMB yield of the MAZ-type zeolites is that the yield is somehow intrinsically linked to the MAZ-type topology $[19,20,29]$. This can be investigated by analyzing the $\mathrm{C}_{6}$ isomer composition of the adsorbed (zeolite) phase under typical $n-\mathrm{C}_{6}$ hydroconversion conditions. Typically, zeolite-based catalysts bring the $\mathrm{C}_{6}$ fraction to gas-phase thermodynamic equilibrium at 523-533 $\mathrm{K}[6,7,19,29]$. There are two distinct descriptions of $\mathrm{C}_{6}$ gas-phase thermodynamic equilibrium available in the literature $[4,67]$. Comparison between experimental data $[5,8,15,65]$ and calculated equilibrium data shows that the more recent description [4] is an improvement over the older one [67] (Table 2). Accordingly, we use the more recent one [4] to define the gas-phase chemical equilibrium compositions at catalytic operating conditions. Based on the gas-phase $\mathrm{C}_{6}$ thermodynamic equilibrium composition, molecular simulations calculate the $\mathrm{C}_{6}$ compositions inside the FAU-, MAZ-, and MOR-type pores in physical equilibrium with such a gas mixture at various $\mathrm{C}_{6}$ pressures (Table 3). As the gas and adsorbed phases are at thermodynamic equilibrium, the adsorbed-phase composition corresponds to the adsorbed-phase thermodynamic equilibrium composition. With increasing pressure, the thermodynamic equilibrium mixture inside the MAZ-type pores contains mostly the shorter DMB, less of the longer MP, and least of the longest $n-\mathrm{C}_{6}$ (Table 3 ). This neatly reflects the differences in packing efficiency (entropy) of these isomers as a result of differences in molecular length [38]. The smaller MOR-type pores exhibit this entropic effect only at a suf-
Table 2

Comparison of the accuracy of two databases $[4,67]$ describing the change in the $\mathrm{C}_{6}$ thermodynamic equilibrium distribution as a function of temperature with experimental values $[5,8,15,65]$ suggests that the more recent database [4] is best ${ }^{\mathrm{a}}$

\begin{tabular}{lcccc}
\hline & $\mathrm{AlCl}_{3}[5]$ & $\mathrm{SO}_{4} \mathrm{Zr}[8]$ & $\mathrm{FeWO}_{x} \mathrm{Zr}$ [15] & $\mathrm{FAU}[65]$ \\
\hline$T(\mathrm{~K})$ & 435 & 473 & 483 & 603 \\
$p \mathrm{C}_{6}(\mathrm{kPa})$ & n.a. & n.a. & 1034 & 776 \\
$\mathrm{H}_{2} / \mathrm{C}_{6}(\mathrm{~mol} / \mathrm{mol})$ & n.a. & n.a. & 2 & 3 \\
Conversion (\%) & 88.5 & n.a. & 86.6 & 79.7 \\
Composition (mol\%) & & & & \\
$n$-C & 11.5 & 14.4 & 14.1 & 20.3 \\
2-MP & 29.5 & 31.5 & 31.3 & 32.8 \\
3-MP & 17.2 & 19.2 & 19.2 & 21.5 \\
2,3-DMB & 11.7 & 9.9 & 9.6 & 8.8 \\
2,2-DMB & 30.1 & 25.1 & 25.8 & 16.7 \\
& & & & \\
$\mathrm{AEQ}(\%)$ [67] & & & 91 & 99 \\
$n$-C & 95 & 97 & 105 & 103 \\
2-MP & $\mathbf{1 1 4}$ & 108 & $\mathbf{1 4 3}$ & $\mathbf{1 2 6}$ \\
3-MP & $\mathbf{1 6 5}$ & $\mathbf{1 4 7}$ & 85 & 88 \\
2,3-DMB & 88 & 87 & 78 & 76 \\
2,2-DMB & 63 & 73 & & \\
AEQ (\%) [4] & & & 100 & 101 \\
$n$-C & 96 & 91 & 98 & 79 \\
2-MP & 103 & 99 & 100 & 77 \\
3-MP & $\mathbf{1 1 1}$ & 101 & 107 & 88 \\
2,3-DMB & 105 & 94 & 100 & 82 \\
2,2-DMB & 79 & 107 & & \\
\hline
\end{tabular}

${ }^{a}$ Chemical equilibrium (\% AEQ) values were calculated by dividing the conversion (for $n-\mathrm{C}_{6}$ ) or yield (for MP and DMB) by its value at thermodynamic equilibrium, and multiplying the ratio by $100 \%$. In boldface are values more than $10 \%$ above the calculated equilibrium that suggest a flaw in the thermodynamic database.

ficiently high pressure. At low pressure understanding the composition is more complicated because it no longer depends solely on molecular length (mainly entropy), but also on differences in molecular diameter (van der Waals interactions that affect both enthalpy and entropy) $[38,39]$. The larger FAU-type pores do not show a strong preference for adsorbing any particular $\mathrm{C}_{6}$ isomer (Table 3 ). In principle, the differences in the Gibbs free energies of adsorption and formation that are the basis of the differences in adsorbedphase isomer composition (Table 3) can translate into differences in shape selectivity. We consider such a translation starting with the four forms of mass transfer shape selectivity, followed by transition state shape selectivity, the fifth form of shape selectivity.

Which form of mass transfer shape selectivity occurs depends on the relative heights of the barrier to diffusion (Figs. 1 and 2). As all five $\mathrm{C}_{6}$ isomers fit easily inside both the 0.74-nm-across MAZ-type pores and the 0.74-nm-across FAU-type windows, neither pore structure imposes a significant barrier to the diffusion of any isomer. If the Gibbs free energy barriers to diffusion are low, (I) reaction intermediate shape selectivity or (II) partial adsorption catalysis cannot play a major role, for they require a very high barrier to diffusion (Fig. 2). This leaves only the two other forms of mass 
Table 3

Molecular simulations yield the adsorbed phase $\mathrm{C}_{6}$ isomer distribution and loading, $L$ ( $\mathrm{mmol} / \mathrm{g})$, at thermodynamic equilibrium at various $\mathrm{C}_{6}$ pressures, $p \mathrm{C}_{6}(\mathrm{kPa})$ at $533 \mathrm{~K}^{\mathrm{a}}$

\begin{tabular}{lcllllll}
\hline & $\begin{array}{l}p \mathrm{C}_{6} \\
(\mathrm{kPa})\end{array}$ & $\begin{array}{l}n-\mathrm{C}_{6} \\
(\mathrm{~mol} \%)\end{array}$ & $\begin{array}{l}2 \mathrm{MP} \\
(\mathrm{mol} \%)\end{array}$ & $\begin{array}{l}3 \mathrm{MP} \\
(\mathrm{mol} \%)\end{array}$ & $\begin{array}{l}2,3-\mathrm{DMB} \\
(\mathrm{mol} \%)\end{array}$ & $\begin{array}{l}2,2-\mathrm{DMB} \\
(\mathrm{mol} \%)\end{array}$ & $\begin{array}{l}L \\
(\mathrm{mmol} / \mathrm{g})\end{array}$ \\
\hline Gas [4] & & 16.7 & 33.0 & 20.8 & 20.8 & 8.6 & \\
FAU & 0 & 11.3 & 31.5 & 20.7 & 29.0 & 7.4 & 0.00 \\
FAU & 600 & 13.1 & 31.3 & 19.7 & 29.5 & 6.4 & 1.26 \\
MAZ & 0 & 7.4 & 26.3 & 19.3 & 25.4 & 21.6 & 0.00 \\
MAZ & 1.5 & 8.0 & 25.5 & 17.9 & 22.3 & 26.2 & 0.02 \\
MAZ & 600 & 4.0 & 18.7 & 16.9 & 29.1 & 31.3 & 0.44 \\
MOR & 0 & 12.5 & 34.3 & 17.4 & 30.2 & 5.6 & 0.00 \\
MOR & 1.5 & 15.1 & 37.1 & 17.9 & 14.2 & 15.6 & 0.02 \\
MOR & 600 & 8.7 & 31.5 & 17.8 & 21.0 & 21.0 & 0.57 \\
\hline
\end{tabular}

a For all simulations we used an identical composition of the gas phase at thermodynamic equilibrium (defined by reference [4]). The adsorbed phase was studied at different total pressures of this $\mathrm{C}_{6}$ gas phase. The zeropressure results are obtained from the Henry coefficients.

transfer shape selectivity for consideration: reactant (III) and product (IV) shape selectivity. When the Gibbs free energy barriers to diffusion are low, the Gibbs free energy of adsorption will dominate the adsorption and desorption rates, and isomers with the lowest Gibbs free energy of adsorption will exhibit the highest adsorption and lowest desorption rates. As 2,3-DMB exhibits a Gibbs free energy of adsorption lower than that of 3-MP (Table 3), 2,3-DMB will adsorb more rapidly and desorb more slowly than 3-MP. This implies that reactant shape selectivity would favor the consumption of rapidly adsorbing 2,3-DMB, and product shape selectivity, the production of rapidly desorbing 3MP. MAZand MOR-type zeolites exhibit neither the correspondingly diminished 2,3-DMB yield nor the enhanced 3-MP yield. In fact, the exact opposite is observed experimentally, for the product slate obtained on both MAZ- and MOR-type zeolites contains more 2,3-DMB and equal or less 3-MP than obtained on a FAU-type zeolite (Table 1) or on sulfated or tungstentated zirconia $[8,15]$, in the absence of shape selectivity. Thus, each of the four forms of mass transfer shape selectivity can be ruled out as a likely candidate to explain the selectivity differences observed between FAU-, MAZ-, and MOR-type zeolites. This leaves only (V) transition state shape selectivity as a possible candidate for explaining the selectivity differences as a form of shape selectivity.

Assessing the potential impact of transition state shape selectivity requires information about the Gibbs free energy of formation of the transition states. In the absence of quantum chemical calculations, one can deduce these Gibbs free energies remarkably successfully by assuming that a higher Gibbs free energy of adsorption of a product corresponds to a higher Gibbs free energy of formation of the relevant transition state $[52,68]$. Usually application of this semi-empirical Brønsted-Evans-Polanyi principle involves only transition state-wall interactions and no intermolecular interactions, so that it estimates adsorption energies at very low pres-
Table 4

Molecular simulations yield the Gibbs free energy of adsorption at very low pressure, $\Delta G_{\text {ads }}(\mathrm{kJ} / \mathrm{mol})$, and afford a comparison of these free energies relative to that of 2,3-DMB, rel. $\Delta G_{\mathrm{ads}}(\mathrm{kJ} / \mathrm{mol})^{\mathrm{a}}$

\begin{tabular}{|c|c|c|c|c|c|c|}
\hline & \multicolumn{2}{|l|}{ FAU } & \multicolumn{2}{|l|}{ MAZ } & \multicolumn{2}{|l|}{ MOR } \\
\hline & $\Delta G_{\mathrm{ads}}$ & rel. $\Delta G_{\mathrm{ads}}$ & $\Delta G_{\mathrm{ads}}$ & rel. $\Delta G_{\mathrm{ads}}$ & $\Delta G_{\mathrm{ads}}$ & rel. $\Delta G_{\mathrm{ads}}$ \\
\hline$n-\mathrm{C}_{6}$ & -17.0 & 3.2 & -20.7 & 7.7 & -25.4 & 2.9 \\
\hline 2-MP & -18.5 & 1.7 & -23.2 & 5.1 & -26.9 & 1.5 \\
\hline 3-MP & -18.7 & 1.5 & -23.9 & 4.4 & -25.9 & 2.4 \\
\hline 2,3-DMB & -20.2 & 0.0 & -28.3 & 0.0 & -28.3 & 0.0 \\
\hline 2,2-DMB & -18.1 & 2.1 & -25.1 & 3.2 & -24.8 & 3.6 \\
\hline
\end{tabular}

a The $\Delta G_{\text {ads }}$ values correspond to the differences in Gibbs free energy of formation induced by the zeolite topology $[38,39,44]$. For MAZ- and MORtype zeolites, the difference in Gibbs free energy for forming 2,2-DMB out of 2,3-DMB are similar, suggesting that the Gibbs free energy of formation of the corresponding transition state is similar [52].

sure and loading. At low loading the differences in Gibbs free energy between 2,3-DMB and 2,2-DMB in both MAZand MOR-type zeolites are virtually identical (Table 4). This suggests that the Gibbs free energy of formation of the transition state for turning 2,3- into 2,2-DMB is the same in both MAZ- and MOR-type zeolite. It implies that the MOR-type pores can readily accommodate the relevant transition state even though the MOR topology contains $0.65 \times$ 0.70 -nm-across windows [66] that are smaller than the 0.74-nm-across MAZ-type zeolite pores [66]. Consistent with this observation, it was recently observed that MOR-type zeolites can accommodate reaction intermediates as bulky as 3,3,5-trimethylheptane just as readily as FAU-type zeolites [21,41]. Accordingly, there is little reason to believe that the reportedly higher-branched hexane yield of MAZ- as compared with MOR-type zeolites (Table 1, Fig. 4) is an instance of (transition state) shape selectivity.

If the differences in hydroisomerization selectivity are not specifically related to differences in zeolite topology, they could correspond to differences in the relative efficiency of the (de)hydrogenation and acid function on the catalyst [41].

\subsection{Does selectivity relate to the relative (de)hydrogenation efficiency?}

For the purpose of the current article we define a (de)hydrogenation function as being less efficient than the acid function, in those instances where the activity of the (de)hydrogenation site is suppressed, the acid site density of a bifunctional catalyst is excessive, or the distance between the (de)hydrogenation site and the acid site is long. When the (de)hydrogenation function is less efficient, there is insufficient competition between the individual alkenes for adsorption at the acid sites, so that the average residence time of alkenes at the acid sites increases $[59,60]$. As a result of a longer average residence time, alkenes undergo multiple acid-catalyzed transformations. This enhances the yield of consecutive reaction products at the expense of the initial reaction products. In $n$-hexane hydroconversion (Fig. 3) this manifests itself as (1) enhanced consecutive 


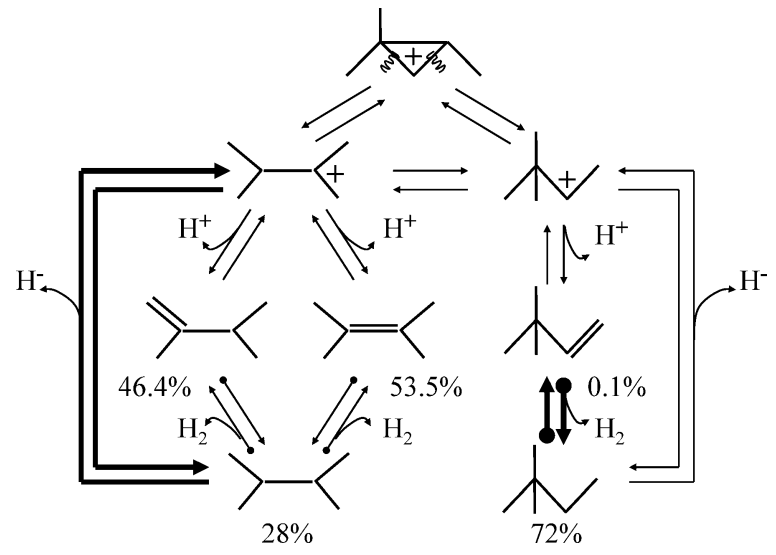

Fig. 5. Sketch of the formation of DMB from the protonated cyclopropyl transition state for 2-MP hydroisomerization (top), including the composition of the dimethylbutene [78] and dimethylbutane fraction [4,67,78] at thermodynamic equilibrium at $533 \mathrm{~K}$. Only the release, and not the uptake of hydrogen, protons, and hydrides is shown. Acid-catalyzed reactions are indicated with $\leftrightarrows$, Pt-catalyzed reactions with $\leftrightarrow$. In marked contrast to 3,3-dimethyl-2-butyl cations, 2,3-dimethyl-2-butyl cations can undergo rapid hydride transfer (bold arrows on the far left) [72]. In marked contrast to 2,3-dimethylbutenes, 3,3-dimethylbutene hydrogenates rapidly (bold arrows on the bottom right) [71]. Thus, a shift in the dominant kinetic pathway from acid-catalyzed hydride transfer to Pt-catalyzed hydrogenation shifts the dominant product from 2,3-DMB to 2,2-DMB. Accordingly, a higher 2,2-DMB yield combined with a lower consecutive reaction product (viz. 2,3-DMB and $\mathrm{C}_{3}$ ) yield is indicative of a more efficient hydrogenation function.

2,3-DMB product yield, and (2) enhanced $\mathrm{C}_{3}$ consecutive hydrocracking product yield $[9,15,63,69,70]$. By the same token, one would expect that a longer alkene residence time also enhances the consecutive 2,2-DMB product yield (Fig. 3). However, the exact opposite is observed: A less efficient (de)hydrogenation function invariably (3) decreases the 2,2-DMB yield $[9,15,63,69,70]$. The reason for this decrease in 2,2-DMB yield with decreasing hydrogenation efficiency is a change in the dominant kinetic pathway from Ptcatalyzed hydrogenation to acid-catalyzed hydride transfer (Fig. 5) $[9,15,28,63]$. Hydrogenation favors 2,2-DMB formation, because 3,3-dimethylbutene hydrogenation is significantly more rapid than 2,3-dimethylbutene hydrogenation [71]. Hydride transfer favors 2,3-DMB formation, because hydride transfer to a 2,3-dimethyl-2-butyl cation is much faster than hydride transfer to the sterically hindered 2,2-dimethyl-2-butyl cation [72] (Fig. 5). Thus, a lower 2,2-DMB yield is indeed a third manifestation of a less effective hydrogenation function. None of the above three manifestations of a less effective hydrogenation function is in any way related to shape selectivity, for they are all well documented for catalysts that do not exhibit shape selectivity [9, $15,63]$.

When comparing the MAZ- and FAU-type zeolites, the former clearly exhibits the first manifestation of a less efficient (de)hydrogenation function (a higher 2,3-DMB yield at the cost of the MP yield). At $72 \% n-\mathrm{C}_{6}$ conversion, the third manifestation of less efficient (de)hydrogenation function (a lower 2,2-DMB in favor of the 2,3-DMB yield) be-
Table 5

Gas-phase thermodynamic equilibrium composition of $\mathrm{C}_{6}$ at $533 \mathrm{~K}$, and $\mathrm{C}_{6}$ product slates reported for various catalysts, at various hydrogen-to-hexane ratios, $\mathrm{H}_{2} / \mathrm{C}_{6}(\mathrm{~mol} / \mathrm{mol})$, hexane pressures, $p_{\mathrm{C}_{6}}(\mathrm{kPa})$, and hydrocracking selectivities, cracking (wt $\%$ )

\begin{tabular}{|c|c|c|c|c|c|}
\hline & Gas [4] & FAU [63] & MAZ [20] & MAZ [29] & MOR [6] \\
\hline$T(\mathrm{~K})$ & 533 & 523 & 533 & 533 & 533 \\
\hline$p_{\mathrm{C}_{6}}(\mathrm{kPa})$ & & 10 & 300 & 600 & n.p. ${ }^{a}$ \\
\hline $\mathrm{H}_{2} / \mathrm{C}_{6}(\mathrm{~mol} / \mathrm{mol})$ & & 9 & 9 & 4 & n.p. \\
\hline Cracking (wt\%) & & 2.1 & 2.0 & 1.7 & n.p. \\
\hline \multicolumn{6}{|l|}{ Composition (mol\%) } \\
\hline$n-\mathrm{C}_{6}$ & 16.7 & 28.8 & 29.1 & 20.0 & 18.1 \\
\hline 2-MP & 33.0 & 29.2 & 28.7 & $29.2^{\mathrm{b}}$ & 31.2 \\
\hline 3-MP & 20.8 & 18.6 & 18.1 & $18^{\mathrm{c}}$ & 21.5 \\
\hline 2,3-DMB & 8.6 & 6.6 & 7.5 & $8.8^{\mathrm{b}}$ & 8.8 \\
\hline 2,2-DMB & 20.8 & 14.7 & 14.6 & $24.0^{\mathrm{b}}$ & 20.3 \\
\hline RON & 71.6 & 62.5 & 62.7 & 70.3 & 70.9 \\
\hline
\end{tabular}

a n.p., not published.

b Calculated from data reported in [29] assuming that thermodynamic equilibrium values were derived from the API database [67].

c A 3-MP value in excess of the API thermodynamic equilibrium was assumed (cf. Table 2) so that the mole percentages of $\mathrm{C}_{6}$ isomers would add up to $100 \%$. The resultant $\mathrm{C}_{6}$ isomer composition reproduces the reported [29] RON number, suggesting that assumptions $b$ and $c$ are correct.

comes apparent (Fig. 4). The MOR-type zeolite exhibits the same manifestations (a higher 2,3-DMB yield at the cost of both the MP and 2,2-DMB yields) more clearly (Table 1) and at a lower conversion (Fig. 4). As far as the second manifestation of a less efficient (de)hydrogenation function is concerned (enhanced hydrocracking selectivity), no data at a high enough $n-\mathrm{C}_{6}$ conversion (where hydrocracking becomes significant [15]) are available to afford a meaningful comparison.

Comparisons of MAZ- and a MOR-type zeolite catalysts reported by other groups $[6,29]$ at higher $n-\mathrm{C}_{6}$ conversion (or lower $n-\mathrm{C}_{6}$ yield, Table 5) further corroborate that there is no unambiguous link between these topologies and $n-\mathrm{C}_{6}$ hydroconversion selectivity. The MAZ-type zeolite exhibits the lowest hydrocracking selectivity at the highest conversion of all zeolite-based catalysts discussed so far (Table 5), indicative of a most efficient (de)hydrogenation function [29]. Not enough is known about the MORtype zeolite catalyst to assess the relative efficiency of its (de)hydrogenation function [6]. However, the similarity of the yield structures obtained on these MAZ- and MORtype zeolite catalysts (Table 5) obviates the need to invoke a difference in topology as a key factor in their $n-\mathrm{C}_{6}$ hydroconversion selectivity.

We attribute the variation in selectivity to differences in the balance between the metal and acid activities of the catalysts. These, in turn, are determined by the catalyst preparation process [7,21-36]. Most of the papers under discussion provide only scant information on the catalyst preparation and characterization, so that it is not possible to evaluate the contributions of each of the critical parameters to the resultant (de)hydrogenation efficiency. 


\section{Conclusions}

It has consistently been reported that MAZ-type zeolite catalysts yield more 2,3-DMB and less MP in $n-\mathrm{C}_{6}$ hydroconversion than a representative FAU-type zeolite. Comparative MOR-type zeolite catalysts reportedly yield even more 2,3-DMB, but less 2,2-DMB. Previously these differences in selectivity were tentatively linked to properties intrinsic to the MAZ- and MOR-type topologies. However, molecular simulations identify no aspect of these zeolite topologies that can satisfactorily account for the reported selectivity differences. A scrutiny of the literature on $n-\mathrm{C}_{6}$ hydroconversion indicates that a more rigorous explanation for the reported selectivity differences is that the efficiency of the (de)hydrogenation function of the MAZ-type zeolite catalysts has consistently been inbetween those of the FAU- and MOR-type zeolite catalysts. The efficiency of the (de)hydrogenation function on the MAZ-type zeolite was low enough to significantly enhance the 2,3-DMB yield relative to the MP yield, but not low enough to significantly decrease the 2,2-DMB yield. Naturally, the efficiency of the (de)hydrogenation function is not a feature inherent to these zeolite topologies.

In view of the apparent difficulty of identifying and preparing a catalyst with a sufficiently active (de)hydrogenation function, one cannot help wondering if FAU-type zeolites have been explored sufficiently to ensure that they do not afford a better base for $n-\mathrm{C}_{6}$ hydroisomerization catalysts than either MAZ- or MOR-type zeolites. At high pressure, the higher pore volume of FAU-type zeolites affords a higher loading (Table 3) that should afford a higher activity (lower operation temperature). Diffusion limitations that decrease the activity with increasing pressure were reported for MOR-type zeolites [73,74], but not for FAU-type zeolites [74]. Contemporary, highly crystalline FAU-type zeolites should facilitate the manufacture of catalysts significantly more active than was feasible previously (cf. [75] and $[63,65])$. The analysis presented in this article should facilitate unambiguously identifying the relative contributions of the acid and the (de)hydrogenation function to the $n-\mathrm{C}_{6}$ hydroconversion selectivity in further studies of FAU-type zeolites.

\section{Acknowledgments}

These investigations are supported in part by The Netherlands Research Council for Chemical Sciences (C.W.) with financial aid from The Netherlands Technology Foundation, by The Netherlands Organization for Scientific Research (NWO) through PIONIER, by ChevronTexaco, and by the Stichting Nationale Computer Faciliteiten (National Computing Facilities Foundation) through use of the supercomputer facilities. We thank the European Commission for an ERG (to S.C.). We thank C. Wilson, C.H. Roemkens,
R. Krishna, A. Kuperman, and S.I. Zones, for their comments on our manuscript.

\section{References}

[1] M.J. Hunter, Erdoel Erdgas Kohle 119 (2003) OG97-OG107.

[2] R.H. Jensen, in: M. Guisnet, J.-P. Gilson (Eds.), Zeolites for Cleaner Technologies, vol. 3, Imperial College Press, London, 2002, pp. 75103.

[3] H. Weyda, E. Kohler, Catal. Today 81 (2003) 51-55.

[4] P.M.M. Blauwhoff, J.W. Gosselink, E.P. Kieffer, S.T. Sie, W.H.J. Stork, in: J. Weitkamp, L. Puppe (Eds.), Catalysis and Zeolites, Springer-Verlag, Berlin, 1999, pp. 437-538.

[5] R.A. Erickson, G.F. Asselin, Chem. Eng. Prog. 61 (1965) 53-58.

[6] H.W. Kouwenhoven, W.C. Van Zijll Langhout, Chem. Eng. Prog. 67 (1971) 65-70.

[7] A. Corma, J. Frontela, J. Lazaro, M. Perez, Prepr. Am. Chem. Soc. Div. Pet. Chem. 36 (1991) 833-840.

[8] T. Hosoi, T. Shimidzu, S. Itoh, S. Baba, H. Takaoka, T. Imai, N. Yokoyama, Prepr. Am. Chem. Soc. Div. Pet. Chem. 33 (1988) 562-567.

[9] E. Iglesia, S.L. Soled, G.M. Kramer, J. Catal. 144 (1993) 238-253.

[10] A. Corma, J.M. Serra, A. Chica, Catal. Today 81 (2003) 495-506.

[11] J.M. Serra, A. Chica, A. Corma, Appl. Catal. A 239 (2003) 35-42.

[12] R.D. Gillespie, M.J. Cohn (Uop Llc, USA), WO2003020420, 2003.

[13] S. Vijay, E.E. Wolf, J.T. Miller, A.J. Kropf, Appl. Catal. A 264 (2004) 125-130.

[14] D.C. Calabro, J.C. Vartuli, J.G. Santiesteban, Top. Catal. 18 (2002) 231-242.

[15] J.G. Santiesteban, D.C. Calabro, C.D. Chang, J.C. Vartuli, T.J. Fiebig, R.D. Bastian, J. Catal. 202 (2001) 25-33.

[16] R.D. Gillespie, F. Xu (UOP Llc, USA), WO2004024319, 2004.

[17] J.Y. Ying, J. Xu (Massachusetts Institute of Technology, USA), WO2003013722, 2003.

[18] F. Raatz, C. Travers, C. Marcilly, T. Descourieres, F. Fajula, F. Figueras (Institut Francais du Petrole, Fr.; Elf France), EP440540, 1991.

[19] F. Fajula, M. Boulet, B. Coq, V. Rajaofanova, F. Figueras, T. Des Courieres, in: L. Guszi, F. Solymosi, P. Tetenyi (Eds.), in: Studies in Surface Science and Catalysis, vol. 75, Elsevier, Amsterdam, 1993, pp. 1007-1018.

[20] J.F. Allain, P. Magnoux, P. Schulz, M. Guisnet, Appl. Catal. A 152 (1997) 221-235

[21] M.M. Olken, J.M. Garces, in: R. Von Ballmoos, J.B. Higgins, M.M.J. Treacy (Eds.), Proceedings, 9th International Zeolite Conference, vol. 2, Butterworth-Heinemann, Stoneham, MA, 1993, pp. 559-566.

[22] M. Tromp, J.A. van Bokhoven, M.T. Garriga Oostenbrink, J.H. Bitter, K.P. de Jong, D.C. Koningsberger, J. Catal. 190 (2000) 209-214.

[23] R. Dutartre, L.C. de Menorval, F. Di Renzo, D. McQueen, F. Fajula, P. Schulz, Micropor. Mater. 6 (1996) 311-320.

[24] S. van Donk, A. Broersma, O.L.J. Gijzeman, J.H. Bitter, K.P. de Jong, in: Studies in Surface Science and Catalysis, vol. 135, 2001, pp. 31123120 .

[25] L.B. Sand, in: R.M. Barrer (Ed.), Molecular Sieves: Papers Read at the Conference Held at the School of Pharmacy, Soc. of the Chemical Industry, London, 1968, pp. 71-77.

[26] F. Raatz, C. Marcilly, E. Freund, Zeolites 5 (1985) 329-333.

[27] M.A. Makarova, A.E. Wilson, B.J. van Liemt, C.M.A.M. Mesters, A.W. de Winter, C. Williams, J. Catal. 172 (1997) 170-177.

[28] H.W. Kouwenhoven, in: W. Meier, J.B. Uytterhoeven (Eds.), Molecular Sieves, vol. 121, Am. Chem. Soc., Washington, DC, 1973, pp. 529_ 539.

[29] D. McQueen, B.H. Chiche, F. Fajula, A. Auroux, C. Guimon, F. Fitoussi, P. Schulz, J. Catal. 161 (1996) 587-596.

[30] A. Martucci, A. Alberti, M.d.L. Guzman-Castillo, F. Di Renzo, F. Fajula, Micropor. Mesopor. Mater. 63 (2003) 33-42. 
[31] M. Kato, K. Itabashi, A. Matsumoto, K. Tsutsumi, J. Phys. Chem. B 107 (2003) 1788-1797.

[32] J. Dedecek, V. Gabova, B. Wichterlova, Stud. Surf. Sci. Catal. B 142 (2002) 1817-1824.

[33] A. Alberti, Stud. Surf. Sci. Catal. 60 (1991) 107-122.

[34] C.N. Satterfield, G.T. Chiu, AIChE J. 20 (1974) 522-529.

[35] J.F. Cole, H.W. Kouwenhoven, Adv. Chem. Ser. 121 (1973) 583-595.

[36] R. Giudici, H.W. Kouwenhoven, R. Prins, Appl. Catal. A 203 (2000) 101-110.

[37] C.R. Marcilly, Top. Catal. 13 (2000) 357-366.

[38] M. Schenk, S. Calero, T.L.M. Maesen, L.L. Van Benthem, M.G. Verbeek, B. Smit, Angew. Chem. Int. Ed. 41 (2002) 2499-2502.

[39] M. Schenk, S. Calero, T.L.M. Maesen, T.J.H. Vlugt, L.L. van Benthem, M.G. Verbeek, B. Schnell, B. Smit, J. Catal. 214 (2003) 88-99.

[40] D.S. Santilli, T.V. Harris, S.I. Zones, Micropor. Mater. 1 (1993) 329341.

[41] T.L.M. Maesen, S. Calero, M. Schenk, B. Smit, J. Catal. 221 (2004) 241-251.

[42] D. Dubbeldam, S. Calero, T.L.M. Maesen, B. Smit, Angew. Chem. Int. Ed. 42 (2003) 3624-3626.

[43] L.A. Clark, M. Sierka, J. Sauer, J. Am. Chem. Soc. 126 (2004) 936947.

[44] T.L.M. Maesen, M. Schenk, T.J.H. Vlugt, B. Smit, J. Catal. 203 (2001) 281-291.

[45] M. Schenk, B. Smit, T.J.H. Vlugt, T.L.M. Maesen, Angew. Chem. Int. Ed. 40 (2001) 736-739.

[46] C.N. Satterfield, J.R. Katzer, W.R. Vieth, Ind. Eng. Chem. Fundam. 10 (1971) 478-486.

[47] C. Perego, S. Amarilli, R. Millini, G. Bellussi, G. Girotti, G. Terzoni, Micropor. Mater. 6 (1996) 395-404.

[48] J.C. Cheng, T.F. Degnan, J.S. Beck, Y.Y. Huang, M. Kalyanaraman, J.A. Kowalski, C.A. Loehr, D.N. Mazzone, Stud. Surf. Sci. Catal. 121 (1999) 53-60.

[49] P.B. Weisz, Pure Appl. Chem. 52 (1980) 2091-2103.

[50] S.M. Csicsery, J. Catal. 23 (1971) 124-130.

[51] S.M. Csicsery, Zeolites 4 (1984) 202-213.

[52] X. Rozanska, R.A. van Santen, T. Demuth, F. Hutschka, J. Hafner, J. Phys. Chem. B 107 (2003) 1309-1315.

[53] D. Dubbeldam, B. Smit, J. Phys. Chem. B 107 (2003) 12138-12152.

[54] A.G. Bezus, A.V. Kiselev, A.A. Lopatkin, P.Q. Du, J. Chem. Soc. Faraday Trans. 274 (1978) 367-379.

[55] R.L. June, A.T. Bell, D.N. Theodorou, J. Phys. Chem. 96 (1992) 10511060.

[56] B. Smit, J.I. Siepmann, J. Phys. Chem. 98 (1994) 8442-8452.
[57] (a) D. Dubbeldam, S. Calero, T.J.H. Vlugt, R. Krishna, B. Smit, J. Phys. Chem. B 108 (2004) 12301-12313;

(b) D. Dubbeldam, S. Calero, T.J.H. Vlugt, R. Krishna, T.L.M. Maesen, E. Beerdsen, B. Smit, Phys. Rev. Lett. 93 (2004) 088302/1088302/4.

[58] P.J. Kuchar, R.D. Gillespie, C.D. Gosling, W.C. Martin, M.J. Cleveland, P.J. Bullen, Int. J. Hydrocarbon Eng. 4 (1999) 50-54, 56-57.

[59] P.B. Weisz, in: D.D. Eley, P.W. Selwood, P.B. Weisz (Eds.), Advances Catalysis, vol. 13, Academic Press, New York/London, 1962, pp. 137190.

[60] H.L. Coonradt, W.E. Garwood, Ind. Eng. Chem. Process Design Dev. 3 (1964) 38-45.

[61] J. Weitkamp, Erdoel Kohle Erdgas Petrochem. 31 (1978) 13-22.

[62] F. Chevalier, M. Guisnet, R. Maurel, in: Proceedings, 6th International Congress on Catalysis, 1977, pp. 478-487.

[63] F. Alvarez, F.R. Ribeiro, G. Giannetto, F. Chevalier, G. Perot, M. Guisnet, Stud. Surf. Sci. Catal. 49 (1989) 1339-1348.

[64] S.J. Miller (ChevronTexaco), WO9857889, 1998.

[65] J.A. Rabo, P.E. Pickert, R.L. Mays, J. Ind. Eng. Chem. 53 (1961) 733 736.

[66] C. Baerlocher, W.M. Meier, D.H. Olson, Atlas of Zeolite Framework Types, Elsevier, Amsterdam, 2001.

[67] F.D. Rossini, K.S. Pitzer, R.L. Arnett, R.M. Braun, G.C. Pimentel, Selected Values of Physical and Thermodynamic Properties of Hydrocarbons and Related Compounds, comprising the tables of API Research Project 44, Carnegie Press, Pittsburg, PA, 1953.

[68] J.K. Norskov, T. Bligaard, A. Logadottir, S. Bahn, L.B. Hansen, M. Bollinger, H. Bengaard, B. Hammer, Z. Sljivancanin, M. Mavrikakis, Y. Xu, S. Dahl, C.J.H. Jacobsen, J. Catal. 209 (2002) 275-278.

[69] M. Guisnet, V. Fouche, M. Belloum, J.P. Bournoville, C. Travers, Appl. Catal. 71 (1991) 283-293.

[70] F. Ribeiro, C. Marcilly, M. Guisnet, J. Catal. 78 (1982) 267-274.

[71] R. Bird, C. Kemball, H.F. Leach, J. Catal. 105 (1987) 199-212.

[72] D.M. Brouwer, J.M. Oelderik, Recueil Trav. Chim. Pays-Bas 87 (1968) 721-736.

[73] F.J.M.M. de Gauw, J. van Grondelle, R.A. van Santen, J. Catal. 204 (2001) 53-63.

[74] J.J. Spivey, P.A. Bryant, Ind. Eng. Chem. Process Design Dev. 21 (1982) 750-760.

[75] D.A. Cooper, E.P. Hertzenberg, W.E. Cormier, T.L.M. Maesen (PQ Holding, Inc., USA), WO2004050548, 2004.

[76] B.L. Evering, R.C. Waugh, J. Ind. Eng. Chem. 43 (1951) 1820-1823.

[77] D.A. McCaulay, J. Am. Chem. Soc. 81 (1959) 6437-6443.

[78] D.R. Stull, E.F. Westrum Jr., G.C. Sinke, The Chemical Thermodynamics of Organic Compounds, 1969. 